\title{
Fenologia reprodutiva de pitaia vermelha no município de Lavras, MG
}

\author{
Reproductive phenology of red pitaya in Lavras, MG, Brazil
}

\author{
Virna Braga Marques ${ }^{I}$ Rodrigo Amato Moreira ${ }^{I^{*}}$ José Darlan Ramos $^{I}$ Neimar Arcanjo de Araújo ${ }^{I}$ \\ Fábio Oseias dos Reis Silva ${ }^{\mathrm{I}}$
}

\begin{abstract}
O estudo do comportamento fenológico pode contribuir para melhorar a produtividade das culturas e a qualidade dos frutos. $O$ trabalho foi realizado com o objetivo de avaliar a fenologia reprodutiva da pitaia vermelha em Lavras, MG, Brasil. Foram avaliados em cem plantas de pitaia vermelha (Hylocereus undatus (Haw.) Britton \& Rose) os períodos das subfases desde a emissão das gemas até a maturação dos frutos de 2008 a 2010. O botão floral se desenvolve no período de 19 a 21 dias. A antese é noturna que dura aproximadamente 15 horas. A maturação do fruto ocorre de 30 a 40 dias após a abertura da flor, quando o fruto adquire a coloração rosa a vermelho intenso e a textura firme. Em Lavras, $M G$ o período reprodutivo da pitaia ocorre de novembro a maio e tempo do aparecimento do botão floral até a colheita do fruto é de 50 a 60 dias.
\end{abstract}

Palavras-chave: Cactaceae, Hylocereus undatus, Pitahaya.

\section{ABSTRACT}

The study of phenology can contribute to improve the productivity of crops and fruit quality. The study was conducted to evaluate the reproductive phenology of red pitaya in Lavras, MG, Brazil. It was evaluated in one hundred plants of pitaya (Hylocereus undatus (Haw.) Britton \& Rose) the subphase's periods from the issuance of buds to fruit ripening from 2008 to 2010. The bud develops from 19 to 21 days. The anthesis is nocturnal which lasts about 15 hours. The maturation occurs from 30 to 40 days after flower opening, when the fruit acquires color pink to deep red and firm texture. In Lavras, $M G$ the reproductive period of red pitaya occurs from November to May and the time of appearance of flower buds to fruit harvest is from 50 to 60 days.

Key words: Cactaceae, Hylocereus undatus, Pitahaya.
A pitaia é uma cactácea originada da América Tropical e Subtropical, pertencente ao grupo de frutíferas tropicais consideradas promissoras para o cultivo. Há algumas décadas, essas plantas eram desconhecidas e atualmente ocupam um crescente nicho no mercado de frutas exóticas da Europa e vêm sendo procuradas, não só pelo exotismo da aparência, como também por suas características organolépticas (LE BELLEC et al., 2006). O Sudeste do Brasil é o principal produtor de pitaia, principalmente a região de Catanduva no Estado de São Paulo, com produção de frutos nos meses de dezembro a maio e produtividade média anual de 14 toneladas de frutos por hectare (BASTOS et al., 2006).

O conhecimento do calendário anual das fenofases e sua variabilidade podem contribuir para melhorar a produtividade das frutíferas e a qualidade dos frutos, podendo deslocar sua produção via técnicas de manejo cultural, em épocas do ano em que ocorra menor incidência de intervenções fitossanitárias que venham a deteriorar a qualidade intrínseca dos frutos (DALASTRA et al., 2009; CAMPAGNOLO et al., 2010). Cada espécie apresenta comportamento diferente em função das condições ambientais, sendo necessários estudos sobre o comportamento das espécies em cada região de cultivo (SEGANTINI et al., 2010).

Dessa forma, o presente trabalho teve por objetivo avaliar a fenologia reprodutiva da pitaia vermelha na região de Lavras, MG, Brasil.

IDepartamento de Agricultura, Universidade Federal de Lavras (UFLA), CP 3037, 37200-000, Lavras, MG, Brasil.

E-mail: amatomoreira@yahoo.com.br. *Autor para correspondência. 
As mudas de pitaia vermelha, com dez meses de idade, (Hylocereus undatus (Haw.) Britton \& Rose) provenientes de matrizes selecionadas e sadias, obtidas por estaquia foram instaladas em junho de 2008. O município de Lavras, MG está situado a $21^{\circ} 14^{\prime} 06^{\prime \prime}$ de latitude Sul e 4500’00” de latitude Oeste, a uma altitude média de $918 \mathrm{~m}$. O clima da região é do tipo Cwb, temperado suave (mesotérmico), segundo a classificação de Köeppen, caracterizado por apresentar inverno seco e verão chuvoso. Os dados climatológicos da época experimental estão apresentados na figura 1 .

A avaliação foi realizada em cem plantas, tutoradas em mourões de eucalipto de dimensões: $15 \mathrm{~cm}$ x $15 \mathrm{~cm}$ x 1,80m de altura, no espaçamento de 3 x 3m, em sistema do tipo latada, sob sol pleno, adubadas trimestralmente com $14 \mathrm{~kg}$ de esterco de curral e $4 \mathrm{~kg}$ de esterco de frango por planta, sem irrigação.

A avaliação fenológica foi realizada de 2008 a 2010. Para avaliação da abertura floral (antese), foram examinadas as flores a cada hora, desde as $17 \mathrm{~h}$ do dia da abertura da flor as $10 \mathrm{~h}$ do dia seguinte, realizadas cinco vezes durante período de avaliação. Após a fecundação, foi observado o período de desenvolvimento do fruto até a maturação.
O florescimento da pitaia vermelha iniciou no verão e o fim da frutificação ocorreu no outono, indicando as altas temperaturas e a precipitação como fatores que estimulam a sua reprodução. A floração compreendeu de novembro a março, com aparecimento de três a cinco surtos de floradas, e a frutificação de janeiro a maio. Dessa forma, observaram-se plantas com botões florais em estágio inicial, botões em desenvolvimento, frutos verdes e maduros em um mesmo período.

Resultados semelhantes foram encontrados por GARCÍA-SUÁREZ et al. (2007) no estudo do crescimento de fruto da pitaya Stenocereus stellatus no México. Esses autores demonstraram que o crescimento dos frutos dessa espécie também é influenciado pelo período chuvoso do ano.

O tempo necessário para desevolvimento do botão floral foi de 19 a 21 dias. Nesse período, ele inicia com diâmetro de 0,5 a 0,7cm (Figura 2A e 2B), começa alongar-se (Figura 2D, 2F, 2G, 2H) até ficar com 26 a $28 \mathrm{~cm}$ de comprimento, quando as sépalas externas começam a se desprender (Figura 2I e 2J). As flores têm antese noturna que dura aproximadamente 15 horas, com o máximo da abertura das 23h a 01h, e o fechamento se inicia nas primeiras horas da manhã (Figuras 2K, 2L, 2M, 2N, e 2O).

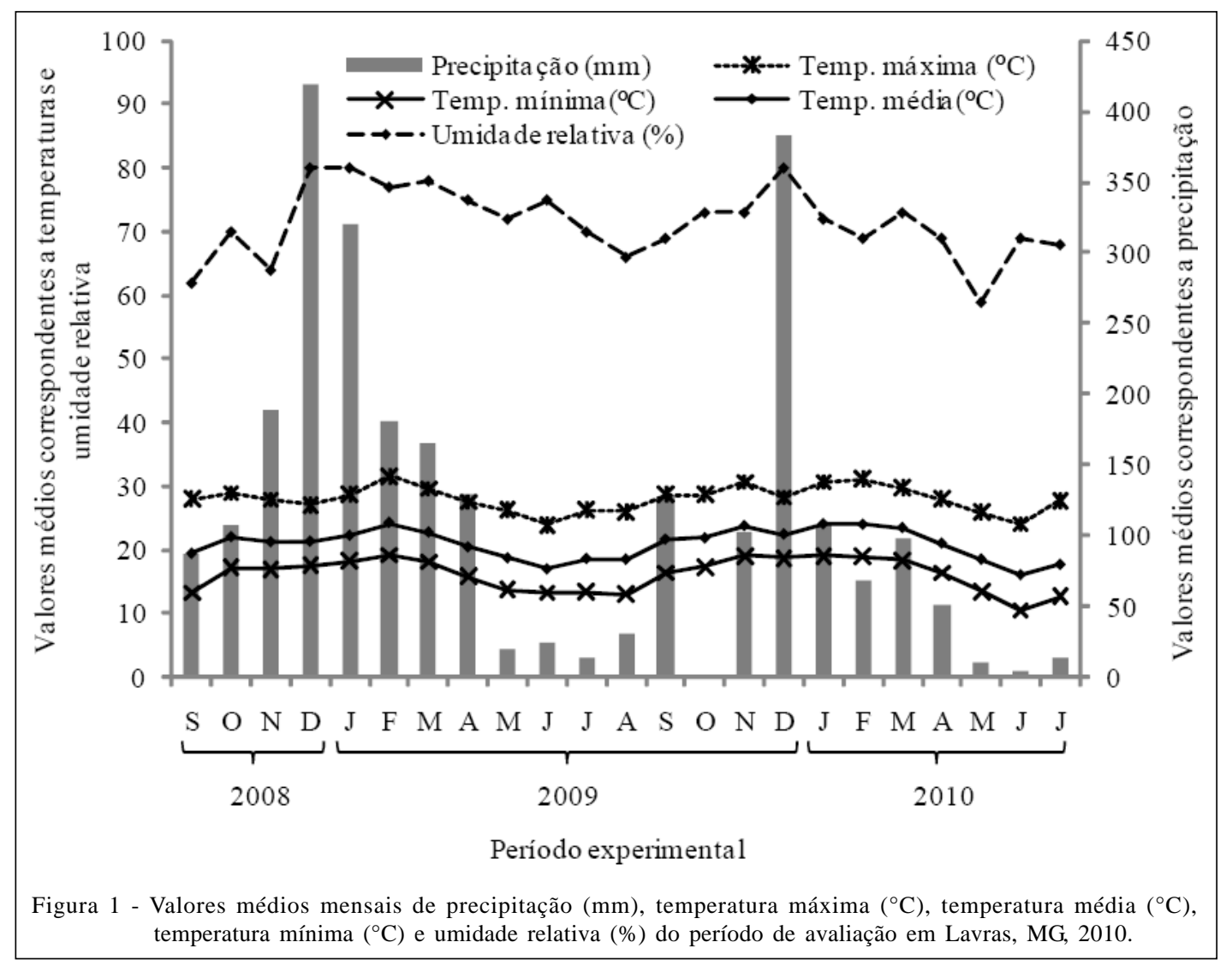

Ciência Rural, v.41, n.6, jun, 2011. 


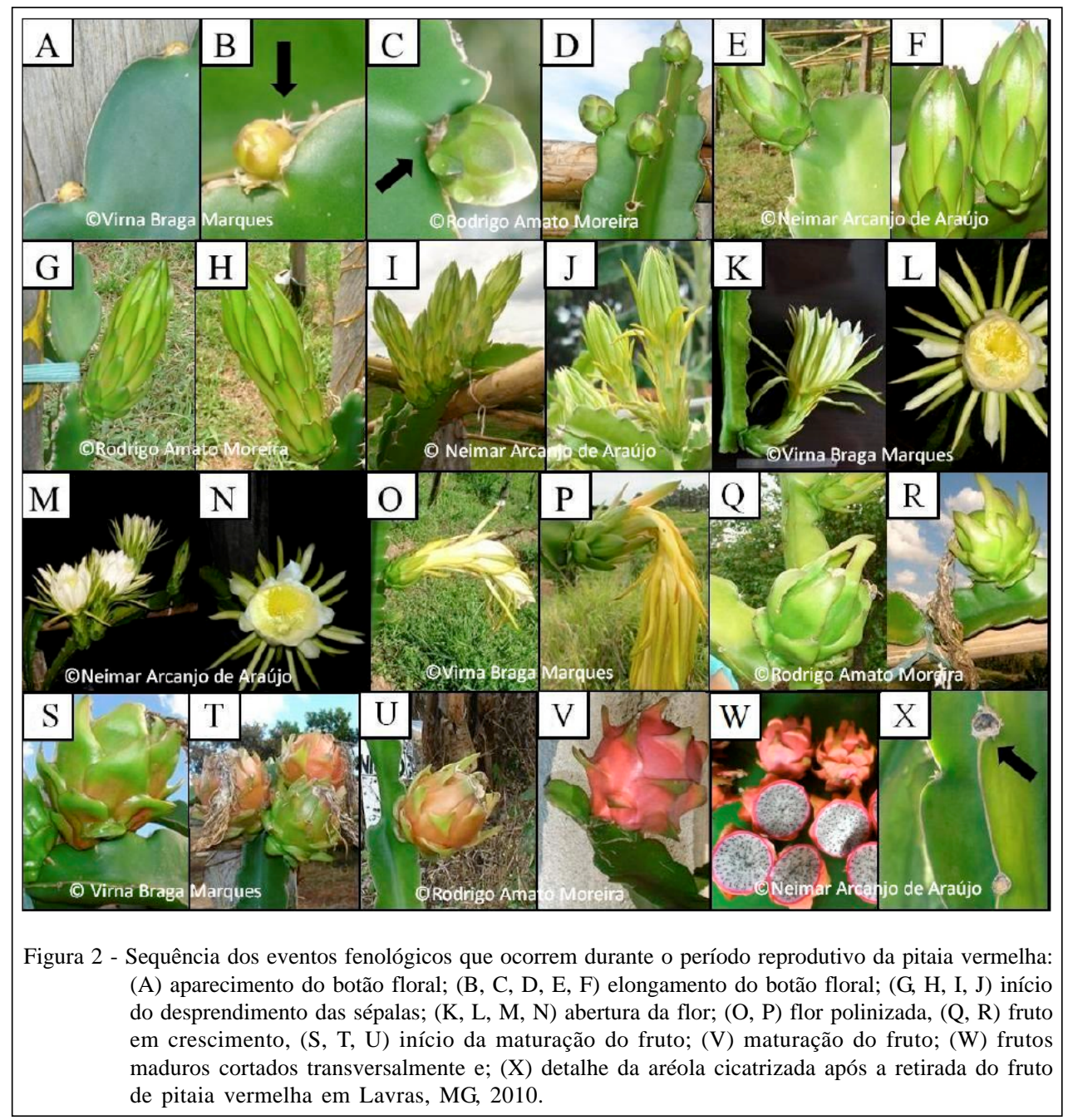

Após a polinização (Figura 2P e 2Q), observa-se o início do desenvolvimento do fruto, que é caracterizado pela dessecação dos restos florais (pétalas, estames e estigma) (Figura 2R) que pode se desprender ou não do fruto até a colheita.

No início do crescimento dos frutos, as brácteas externas, que são extensões do pericarpo, recobrem completamente os frutos (Figura 2Q), com o aumento do volume do fruto elas diminuem (Figura 2R, $2 \mathrm{~S}, 2 \mathrm{~T}, 2 \mathrm{U}$ ) e, mesmo depois do fruto ter adquirido a sua coloração final - rosa a vermelho intenso -, elas se mantêm verdes, contrastando com o fruto (Figura 2V). A maturação fisiológica do fruto de pitaia é iniciada com a primeira manifestação da coloração vermelha na casca (CASTILLO \& ORTIZ, 1994).

A maturação completa do fruto ocorre de 30 a 40 dias após a abertura da flor, quando o fruto adquire a coloração de rosa a vermelho intenso, polpa branca, com textura ainda firme (Figura $2 \mathrm{~V}$ e $2 \mathrm{~W}$ ). O tempo decorrido para o desenvolvimento do fruto nas condições de Lavras é semelhante ao observado por YAH et al. (2008) em pitaia Hylocereus undatus no México, que verificaram a maturação completa dos frutos aos 31 dias após abertura floral.

Após a retirada do fruto, a gema de onde ele se originou perde a função de se diferenciar e não pode mais dar origem a nenhum outro órgão, seja vegetativo ou reprodutivo, restando uma cicatriz no lugar (Figura $2 \mathrm{X}$ ). Por ser uma cultura perene, os eventos fenológicos observados se repetem a cada ano, conforme apresentados na tabela 1.

O período da emissão do botão floral até a maturação dos frutos compreendeu cerca de 50 a 60 dias. Esse tempo pode variar em função da região de cultivo, pois, nas condições do México, o ciclo reprodutivo compreende de 39 a 52 dias (CASTILHO \& ORTIZ, 1994), provavelmente pelas condições climáticas terem influenciado no comportamento fenológico das plantas (SEGANTINI et al., 2010). 
Tabela 1 - Fases da fenologia reprodutiva da pitaia vermelha em Lavras, MG, 2010.

\begin{tabular}{|c|c|c|}
\hline Fases & Subfases & Período \\
\hline \multirow{3}{*}{ Florescimento } & 1. Emissão das gemas ao início do aparecimento do botão floral (evolução da gema floral) & 19-21 dias \\
\hline & 2. Elongação da flor & 1-2 dias \\
\hline & 5. Abertura floral & 15 horas \\
\hline \multirow{3}{*}{ Frutificação } & 6. Vingamento do fruto & 2-4 dias \\
\hline & 7. Crescimento do fruto & 23-27 dias \\
\hline & 8. Maturação do fruto & 5-6 dias \\
\hline \multicolumn{2}{|c|}{ Período do florescimento à maturação do fruto } & $50-60$ dias \\
\hline
\end{tabular}

Em Lavras, MG, o período reprodutivo da pitaia vermelha ocorre de novembro a maio e o tempo do aparecimento do botão floral até a colheita do fruto é de 50 a 60 dias.

\section{REFERÊNCIAS}

BASTOS, D.C. et al. Propagação de pitaya vermelha por estaquia. Ciência e Agrotecnologia, v.30, n.6, p.11061109, 2006. Disponível em: <http://www.scielo.br/ scielo.php? script=sci arttext \& pid=S 1413 70542006000600009\&lng=en\&nrm=iso >. Acesso em: 14 mar. 2011. doi: 10.1590/S1413-70542006000600009.

CAMPAGNOLO, M.A. et al. Sistema desponte na produção de figos verdes 'Roxo de Valinhos'. Ciência Rural, v.40, n.1, p.25-29, 2010. Disponível em: <http://www.scielo.br/ scielo.php ? script =sci_arttext \& pid=S 0103 $84782010000100005 \& \operatorname{lng}=$ pt\&nrm=iso $>$. Acesso em: 30 abr. 2011. doi: 10.1590/S0103-84782009005000219.

CASTILLO, M.R; ORTIZ, Y.D. Floración y fructificación de pitajaya en Zaachila, Oaxaca. Revista Fitotecnia Mexicana, v.17, p.12-19, 1994.

DALASTRA, I.M. et al. Épocas de poda na produção de figos verdes 'Roxo de Valinhos' em sistema orgânico na região oeste do Paraná. Revista Brasileira de Fruticultura, v.31, n.2, p.447-453, 2009. Disponível em: <http://www.scielo.br/ scielo.php? script =sci_arttext\&pid=S 0100 29452009000200019\&lng=pt\&nrm=iso >. Acesso em: 30 abr. 2011. doi: 10.1590/S0100-29452009000200019.

LE BELLEC, F. et al. Pitahaya (Hylocereus spp.): a new crop, a market with a future. Fruits, v.61, n.4, p.237-250, 2006. Disponível em: <http://pdfcast.org/pdf/pitahaya-hylocereus-sppa-new-fruit-crop-a-market-with-a-future>. Acesso em: 02 mar. 2011. doi: 10.1051/fruits:2006021.

GARCÍA-SUÁREZ, F. et al. Pitaya (Stenocereus stellatus) fruit growth is associated to wet season in Mexican dry tropic. Phyton, v.76, p.19-26, 2007. Disponível em: <http:// www.scielo.org.ar/pdf/phyton/v76/v76a02.pdf >. Acesso em: 28 mar. 2011.

SEGANTINI, D.M. et al. Fenologia da figueira-da-índia em Selvíria - MS. Revista Brasileira de Fruticultura, v.32, n.2, p.630-636, 2010. Disponível em: <http://www.scielo.br/ scielo.php? script=sci_arttext\&pid=S 0100 29452010000200038\&lng=en\&nrm=iso>. Acesso em: 15 mar. 2011. doi: 10.1590/S0100-29452010005000049.

YAH, A.R.C. et al. Cambios físicos, químicos y sensoriales en frutos de pitahaya (Hylocereus undatus) durante su desarrollo. Revista Fitotecnia Mexicana, v.31, n.1, p.1-5, 2008. Disponível em: <http://www.revistafitotecniamexicana.org/ documentos/31-1/1a.pdf>. Acesso em: 20 mar. 2011. 